\title{
Risk And Return: New Insights For Theory, Measurement And Management
}

Frantz Maurer, University Montesquieu-Bordeaux IV, IRGO \& Bordeaux Management School, France

\begin{abstract}
This study investigates the risk-return relationship by using an ordinal strategic risk measure of risk rather than the more conventional variance-based measures. A set of hypotheses is specified linking ordinal strategic risk, return, and organizational slack. Empirical results are interesting in that they allow elaborating the idea that strategic risk may have a positive effect on subsequent performance and that performance has a negative effect on subsequent risk. Such a self-correcting cycle offers an interesting contrast to the "vicious circle" proposed by previous risk-return research based on prospect theory. Overall, this paper suggests that new conceptual and methodological risk approaches are needed to better understand the risk taking process in organizations.
\end{abstract}

Keywords: Bowman's Paradox; Ordinal Risk; Risk/Return Relationship; Prospect Theory; Behavioral Theory of the Firm.

\section{INTRODUCTION}

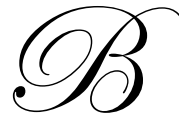

owman's seminal work $(1980,1982)$ pointed out the theoretical and empirical contradictions between corporate risk-return relations and the positive risk-return relations derived from modern financial portfolio theory. The so-called Bowman's paradox has stimulated a rich stream of research and continues to fascinate strategy scholars (e.g., Andersen, Denrell and Bettis, 2007; Fiegenbaum and Thomas, 2004; Miller and Chen, 2003, 2004; Wang, Barney, and Reuer, 2003).

According to Bowman, behavioral theory provides a possible explanation for the paradoxical patterns observed in corporate risk-return studies. Sparked by Bowman's intuition, other researchers sought to empirically test hypotheses derived from behavioral explanations of managerial risk avoidance and risk seeking ${ }^{1}$. As indicated by Andersen, Denrell and Bettis (2007: 408), there are three widely accepted explanations for Bowman's risk-return paradox: (1) contingencies that influence the risk behavior of organizational decision-makers; (2) outcomes from strategic conduct; and (3) statistical artifacts. Here we pursue the view that higher risk seems to cause higher performance, thus leading to virtuous performance cycle over time. Our results are in line with the strategic conduct perspective as they suggest that inverse risk-return relationships could be the result of good management practices.

The primary objective of this study is to model the impact of past performance on risk taking and the impact of risk taking on subsequent performance. We draw from the process theory of organizational decision making (Cyert and March, 1963) to develop testable hypotheses regarding relations between risk and firm performance. These relations become explicit in a two-equation model of relations between risk and return allowing for moderating effects associated with organizational slack.

To our best knowledge, empirical studies examining risk-return models by using conceptualizations and risk measures different from a variance-based approach, are quite rare. We use here the ordinal strategic risk

\footnotetext{
${ }^{1}$ For comprehensive reviews of the literature we refer the interested reader to Bromiley, Miller, and Rau (2001) and Nickel and Rodriguez (2002).
} 
measure originally developed by Collins and Ruefli (1992). Within their framework, risk is defined in terms of the probability of losing rank position vis a vis the other firms in a reference set.

In line with the research stream initiated by Singh (1986), and then developed by Bromiley (1991) and Miller and Leiblein (1996), we provide an alternative approach to analyze risk-return relationships. This study seeks to further this line of research, testing for possible ties between risk taking and future economic performance.

\section{THEORY AND HYPOTHESES}

Cyert and March (1963) viewed firms as large systems of standard operating procedures or routines. Managers in firms have both levels of performance they aspire to and levels of performance they except. According to Cyert and March, when performance falls below the level of aspirations, firms respond by initiating searches for alternative routines. Such managerial attention to performance that falls short of a target level is consistent with "chance of loss" conceptualization of risk underlying ordinal strategic risk. Deficiencies in performance relative to aspirations stimulate searches designed to generate alternatives that will resolve performance crisis. The behavioral theory of the firm suggests that search continues in a sequential fashion until the organization encounters an alternative with an expected performance exceeding the aspiration level. It is assumed that that the profit generated by this solution more than offsets the short-term cost associated with search. The behavioral theory of the firm suggests a failure to reach aspired-to performance levels will result in new routines that lead to improved subsequent performance.

A first hypothesis tests the effect of ordinal strategic risk on organizational performance. The more interesting issue is whether or not ordinal strategic risk results in a relative improvement in a firm's own performance. The authors of much of the literature on innovation, organizational change, and general management have assumed that change and risk taking have a positive influence on future performance (e.g. Aaker and Jacobson, 1987). In general, economic analyses have argued that firms need to be compensated for taking risks with high returns.

Hypothesis 1: Ordinal strategic risk has a positive influence on future financial performance.

The behavioral argument underlying Hypothesis 1 rests on the assumption that ordinal strategic risk focuses manager's attention on problem solving and that ensuing search results in the identification and implementation of a performance-enhancing alternative strategy. As Cyert and March (1963: 278) stated, "We have argued that failure induces search and search generally results in solutions." A plausible alternative to Hypothesis 1 is that firms are dominated by inertia and fail to respond to ordinal strategic risk with performance-enhancing changes. The view that inertia, rather than managerial strategic choice, characterizes firms is most strongly asserted in population ecology (Hannan and Freeman, 1977). The absence of empirical support for the hypothesized positive relation between ordinal strategic risk and future performance would be consistent with the inertia hypothesis. It should be noted that changes in strategy mediate the relation between ordinal strategic risk and future financial performance and, hence, the hypothesized relation between these two constructs is not directly causal.

The direct impact of performance on risk taking is central to work by Bowman $(1980,1982)$ and by Fiegenbaum and Thomas $(1986,1988)$ and was significant in Bromiley's (1991) research. Behavioral theorists motivated by prospect theory (Kahneman and Tversky, 1979) have contended that poor performers are more likely than high performers to engage in risky strategies. Prospect theory suggests that poorly performing firms may take greater risks than strongly performing firms. Such risky strategies may have low expected values, but the firms expect eventually that some strategic gamble will improve firm performance. Strong performers, on the other hand, will reduce their risk-taking strategic initiatives.

In an examination of players' responses to a strategic marketing game, Lant and Montgomery (1987) found that performance below aspirations resulted in riskier choices (risk was formulated as variance or uncertainty) and more innovative search than performance that met or exceeded aspirations. Fisher and hall (1969) presented an economic argument for the impact of performance on risk taking. They concluded that, "earnings should be larger, 
on the average, for firms with greater variations in their earnings than for firms with little earnings variability" (1969: 82). Overall, these arguments support the contention that strong financial performance decreases ordinal strategic risk and that poor performance increases it.

Hypothesis 2: Financial performance has a negative influence on future ordinal strategic risk.

The behavioral theory of the firm introduces organizational slack as a moderator of organizational response. Slack defines excess resources that a firm can use to loosen the ties between environmental changes and the need for organizational responses. Organizational slack resources accumulate during periods of performance above aspirations and diminish during periods of unsatisfactory performance. Slack determines a firm's motivation to seek out revenue-enhancing changes in operating routines and strategies in response to performance shortfalls. High-slack firms are less likely to undertake searches for new strategies when faced with ordinal strategic. Ordinal strategic risk has thus a less positive impact on future financial performance for high-slack firms than for low-slack firms.

The direct influence of slack on future performance is unclear (Cyert and March, 1963: 279). Slack may be seen as wasted resources, so that firms with high levels of slack should result in low performance. But such a slackperformance association is static. It says nothing about the influence of slack on future financial performance when current performance is controlled. Slack also allows firms the ability "to take advantage of opportunities afforded by the environment" (Thompson, 1967: 150). Firms with additional resources have more strategic options available than firms without resources. Alternatively, a lack of slack may force a firm to manage very carefully. Firms with levels of slack substantially below the normal for their industry may be expected to find ways to reduce costs and improve performance. Firms with much slack obtain a competitive advantage and firms with little slack must manage carefully. Either action should increase performance.

Hypothesis 3: Slack increases future financial performance.

The influence of slack on risk taking depends on the relation of slack to a target level of slack (March and Shapira, 1987). If slack falls substantially below its target level, managers take risks in order to create additional slack (Cyert and March, 1963; MacCrimmon and Wehrung, 1986). Alternatively, if slack is around the target level, managers take few risks. They see their firm as operating in a satisfactory manner and continue with conventional routines (Cyert and March, 1963).

Regarding the direct effect of slack on ordinal strategic risk, the presence of slack resources is expected to allow firms to undertake investments reducing subsequent ordinal strategic risk. Firms with slack resources formulate responses to a greater range of environmental contingencies than do resource-constrained firms (Cohen, March, \& Olsen, 1972). In so doing, high-slack firms reduce their ordinal strategic risk relative to low-slack firms.

Hypothesis 4: Slack reduces future ordinal strategic risk.

\section{METHODOLOGY}

\section{Model Specification}

The model consists of two equations. The primary relations are those between risk and future performance and the effect of performance on future risk. The time period subscripts indicate the time lags incorporated in the model. The hypotheses under each regression equation summarize the expected relations developed in the previous section. Previous return in equation [A] below controls for firm-specific historical effects. Similarly, equation [B] includes past risk to control for firm-specific historical influences on risk. The two equations are as follows:

Return $_{t}=\alpha_{0}+\alpha_{1}$ risk $_{t-1}+\alpha_{2}$ slack $_{t-1}+\alpha_{3}$ return $_{t-1}+\alpha_{4}$ industry return $_{t}+\varepsilon_{t}$.

For Hypothesis $1, \alpha_{1}>0$; for Hypothesis $3, \alpha_{2}>0$. 
Risk $_{t}=\beta_{0}+\beta_{1}$ return $_{t-1}+\beta_{2}$ slack $_{t-1}+\beta_{3}$ risk $_{t-1}+\beta_{4}$ industry risk $k_{t}+\varepsilon_{t}$.

For Hypothesis $2, \beta_{1}<0$; for Hypothesis $4, \beta_{2}<0$.

Controls. The lagged dependent variable and contemporaneous industry effects are included in the model as controls for other variables that have an impact on risk and return but are not explicitly considered in the behavioral theory of the firm. The risk and return variables are expected to be positively related with the same variables in the subsequent period $\left(\alpha_{3}>0, \beta_{3}>0\right)$. The lagged dependent variables express the ordinal strategic risk-return relations in the context of a firm's prior risk and return.

The contemporaneous industry effect controls for difference in performance and risk across industry categories. Previous research has indicated the importance of industry controls in modeling risk-return relations (e.g. Bowman, 1980; Fiegenbaum and Thomas, 1986). Contemporaneous measures of risk and return serve as proxies for the attractiveness of an industry's structure. The industry return (risk) term in the return (risk) equation includes contemporaneous performance (risk) by all other firms in the same two-digit Standard Industrial Classification (SIC) industry $^{2}$. If industry structure affects performance, average returns by other firms in the industry should be positively related to returns for any particular firm $\left(\alpha_{4}>0\right)$. A general decline in industry performance would raise industry ordinal strategic risk. Ordinal strategic risk is expected to be positively related to ordinal strategic risk for a particular firm in the industry $\left(\beta_{4}>0\right)$.

Lag structure. Although it has been widely argued that risk affects return and vice and versa, one of the difficulties in specifying a model of risk-return relations is inadequate understanding of the timing of these effects. Most previous studies in the strategy field made causal arguments relating risk and return but model risk and return as having contemporaneous effects on each other. An alternative to estimating contemporaneous risk-return relations is to specify a lagged model in which risk affects future return and vice versa. As Miller and Leiblein (1996) pointed out, given the unique characteristics of firms, it would be difficult to make any generalization regarding the appropriateness lag structure for risk-return relations.

Miller and Bromiley (1990) and Miller and Leiblein (1996) found significant relations using a model in which risk in one five-year period explained return in the subsequent period. Bromiley (1991) modeled risk in one year as affecting return in the following year and vice versa. Although other lag structures may be reasonable, this study uses five-year periods to specify the lags in modeling risk-return relations. The slack, industry risk, and industry return variables were also computed over a five-year period.

\section{Measures And Sample}

Return. Return on equity (ROE) and return on assets (ROA) are two common accounting-based measures of performance. Both measures are highly correlated. Furthermore, both have been used to compute highly correlated accounting-based risk measures in previous strategy research (Miller and Bromiley, 1990). This study uses average ROA over the five-year period as the return measure.

Strategic Risk. Risk in this study is based on the ordinal approach developed by Collins and Ruefli (1992). As a starting point, an intuitive feel for the ordinal context can be obtained by thinking of a set of firms that are ranked against each other annually for a period of time on the basis of a dimension selected as being appropriate to the research. We used annual ROA as the criteria for ranking firms' performance. In this context, favorable events are those that yield an improvement in rank, while unfortunate events are those that result in a loss of rank. An event of performance within an ordinal system is defined by four parameters: the firm (I), which is an entity of the system, its row of initial classification (J), its row of final classification (K), and the time (T) of event completion. All of which can be represented in a matrix of events, $\Phi=\left[\Phi_{\mathrm{IJ,K}, \mathrm{T}}\right]$. This matrix $\Phi$ is simply a set of all possible events or transitions which might occur in the system under observation.

\footnotetext{
${ }^{2}$ A firm's own return (risk) is not included in the industry return (risk) for that observation.
} 
We compute firms' ordinal strategic risk relative to a benchmark corresponding to the target level of risk for a firm. This benchmark is defined as the ordinal strategic risk for the reference set of firms-The French CAC 40 stock market index-used in this study. A detailed presentation of this method is out of the scope of this research. For the interested reader, Appendix contains the computational procedure used to generate an ordinal measure of a firm's strategic risk.

Organizational slack. There is theoretical support for the relevance of reference levels in specifying slack. Bourgeois (1981) contended that changes in the amount of organizational slack over time, rather than absolute levels of slack, are relevant to explaining firm behavior. Similarly, Bromiley (1991) and March and Shapira (1987) argued the influence of slack on performance and risk depends not on the absolute level of slack but on slack relative to a target level.

Financial ratios such as those commonly used as slack indicators differ across industries. Ratios that are the norm in one industry may be exceptionally high or low in another. Slack measures may not generalize across industries. According to Lev (1969), average industry financial ratios offer reasonable proxies for target levels. In this study, we measured slack as the ratio of a firm's own accounting measure to its industry average (at the twodigit SIC level). Following Bourgeois (1981), we measured recoverable slack using the following ratios: (i) accounts receivable/sales, inventory/sales, and selling, general, and administrative expenses/sales. In each case, we computed normalized measures consisting of a firm's ratio divided by the two-digit SIC industry average ratio.

Bourgeois and Singh (1983) also identified measures of both available and potential slack. Following Miler and Leiblein (1996), we chose to focus on recoverable slack because it is the most relevant concept of slack for many organizational stakeholders. Because of the immediate impact of recoverable slack on operations, constraints on recoverable slack are likely to be more salient to managers than constraints on potential or available slack.

The aggregate recoverable slack measures for a given year consisted of an unweighted sum of the three standardized recoverable slack indicators. The slack measure used for model estimation was a firm's mean recoverable slack calculated over a five-year period.

Sample. The sample consisted of all firms belonging to the French CAC 40 stock market index for which the necessary accounting data were available in the OSIRIS database during the years 1988 through 2002 . We defined three periods corresponding to the five-year time segments of 1988-92, 1993-97, and 1998-02. Firms with returns or any organizational slack indicator beyond three standard deviations from the annual mean across all firms were considered outliers and eliminated from that year's data set. The final sample includes thirty eight firms out of a total of forty belonging to the French CAC 40.

The choice of the French CAC 40 as the reference set of firms or system may limit the generality of the findings. Whilst there are a little bit more of thousand firms quoted on the French stock market, the CAC 40 index is a very meaningful indicator of the overall financial and economic wealth of the country. As for the American S\&P 500 index, firms included in the CAC 40 are among the strongest stock market capitalizations of the French financial market. Ordinal strategic risk-return relations observed from a CAC 40 sample may be interesting in their own right and also suggest a number of additional studies in different environments.

\section{RESULTS}

Table 1 presents descriptive statistics and Pearson correlations between return, ordinal strategic risk, organizational slack, and the control variables for each of the three periods. Industry return and industry ordinal strategic risk denote the average ROA and ordinal strategic risk for all firms in the same two-digit SIC industry (excluding the firm under observation). These two industry average variables serve as controls in the regression models. Table 1 indicates significant negative correlations between ordinal strategic risk and return. 
Table 1

Descriptive statistics and Correlations by Period

\begin{tabular}{|c|c|c|c|c|c|c|}
\hline Variables & Mean & S.d. & 1 & 2 & 3 & 4 \\
\hline \multicolumn{7}{|l|}{ Period 1: 1988-92 } \\
\hline 1. Return & 5.853 & 3.751 & & & & \\
\hline 2. Ordinal strategic risk & -0.003 & 0.114 & $-.576^{* *}$ & & & \\
\hline 3. Industry return & 6.706 & 3.133 & $.501^{* *}$ & $-.407^{*}$ & & \\
\hline 4. Industry ord. strategic risk & 0.903 & 0.780 & $-.535^{* *}$ & $.526^{* *}$ & $-.652^{* * * *}$ & \\
\hline 5. Organizational slack & 0.227 & 0.116 & -.242 & -.121 & .194 & .222 \\
\hline \multicolumn{7}{|l|}{ Period 2 : 1993-97 } \\
\hline 1. Return & 4.839 & 3.571 & & & & \\
\hline 2. Ordinal strategic risk & -0.007 & 0.088 & $-.771^{* * * *}$ & & & \\
\hline 3. Industry return & 6.777 & 3.316 & $.513^{* *}$ & -.111 & & \\
\hline 4. Industry ord. strategic risk & 0.442 & 0.297 & -.114 & $.417^{*}$ & $-.768^{* * * *}$ & \\
\hline 5. Organizational slack & 0.189 & 0.108 & -.217 & $.419^{*}$ & .192 & $.397^{*}$ \\
\hline \multicolumn{7}{|l|}{ Period 3 : 1998-02 } \\
\hline 1. Return & 5.739 & 3.912 & & & & \\
\hline 2. Ordinal strategic risk & -0.001 & 0.092 & $-.457^{* *}$ & & & \\
\hline 3. Industry return & 5.116 & 2.886 & $.562^{* *}$ & -.161 & & \\
\hline 4. Industry ord. strategic risk & 0.129 & 0.901 & -.124 & $.455^{* *}$ & $-.644^{* * * *}$ & \\
\hline 5. Organizational slack & 0.165 & 0.083 & $-.393^{*}$ & .163 & -.349 & .348 \\
\hline
\end{tabular}

${ }^{*} \mathrm{p}<.05 ;{ }^{* *} \mathrm{p}<.01 ;{ }^{* * *} \mathrm{p}<.001$

Initial regression results for equations [1] and [2] indicated outlier observations may have unduly influenced the estimated coefficients. Outliers were eliminated if their influence statistics, DFFITS, indicated very influential observations ${ }^{3}$. Elimination of outliers resulted in deletion of two observations in the original sample observations. A comparison of the regression results before and after elimination of outliers indicated no substantive differences in the signs or magnitudes of the estimated coefficients.

Tables 2 and 3 present ordinary-least-squares results after elimination of the two outliers) for the return and risk regression equations, respectively. The column headings indicate the period of the dependent variable. For each period, the estimated standardized coefficients are displayed. When independent variables included in a linear regression model are correlated (as shown in Table 1), it may be very uneasy to isolate the individual influence of each one on the dependent variable. The standardized coefficients allow a better estimation of the respective influence of the independent variables on the dependent one. Basically, standardized coefficients are those obtained, if, prior to regression estimation, the independent variables were standardized (Z-score).

\footnotetext{
${ }^{3}$ Regression analyses were carried out using the SPSS data analysis software. The DFFITS statistic is a scaled measure of the change in the predicted value for a given observation with and without including the observation in the model estimation. Large DFFITS values indicate very influential observations. Observations are thought to unduly affect model estimations when their DFFITS value exceeds $2 \sqrt{p / n}$, where $p$ is the number of parameters in the model and $n$ is the number of observations (Belsey, Kuhn, \& Welsch, 1980).
} 
Table 2

Results of Regression Analyses for Return

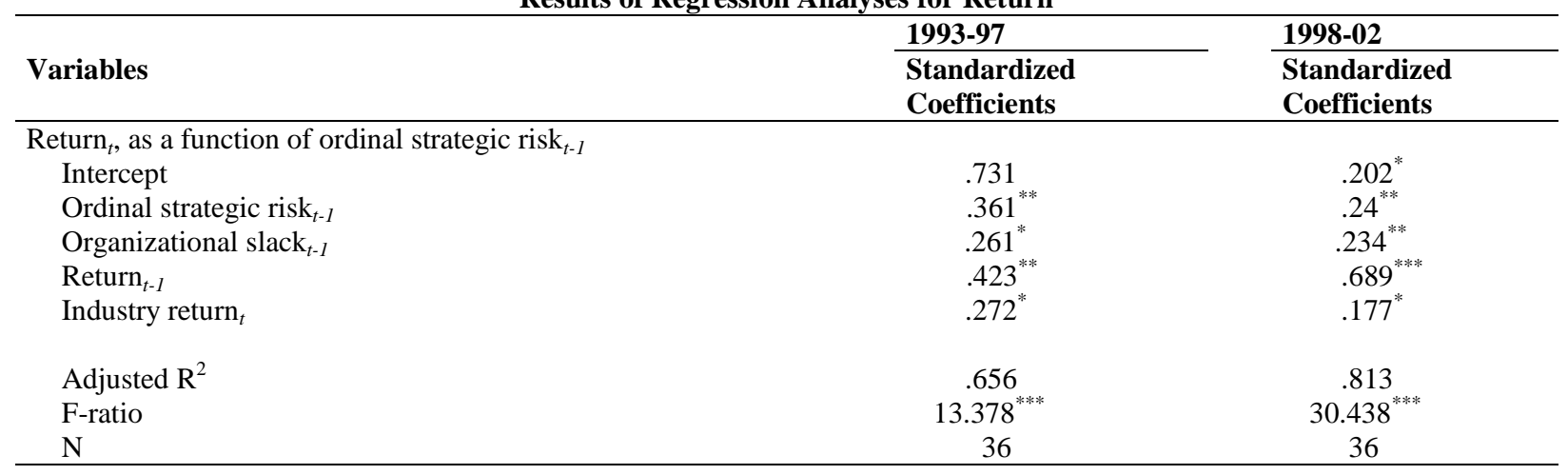

${ }^{*} \mathrm{p}<.05 ;{ }^{* *} \mathrm{p}<.01 ;{ }^{* * *} \mathrm{p}<.001$

Table 3

Results of Regression Analyses for Risk

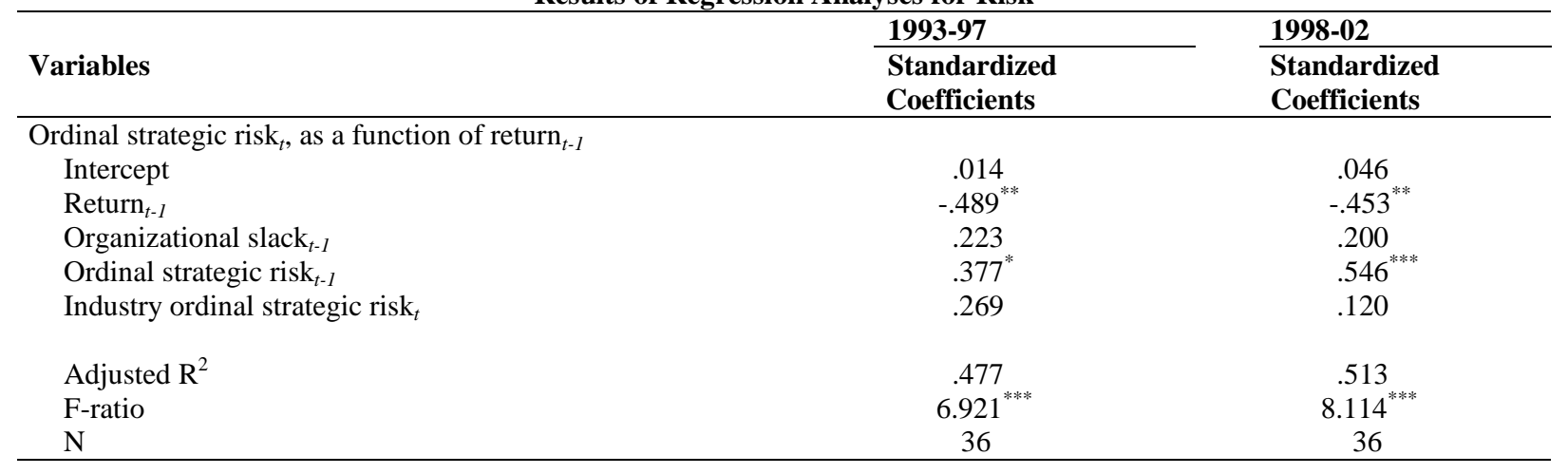

${ }^{*} \mathrm{p}<.05 ;{ }^{* *} \mathrm{p}<.01 ; * * * \mathrm{p}<.001$

The significant correlations among the independent variables evident in Table 1 motivated assessment of potential collinearity problems. Examinations of both the variance inflation factors and conditioning index statistics provided diagnostics well below the suggested guidelines, indicating collinearity did not present serious problem for model estimation. ${ }^{4}$.

Hypothesis 1 states that ordinal strategic risk should have a positive relation with subsequent financial performance. The signs of the coefficients associated with ordinal strategic risk for the two five-year periods (Table 2) are positive, supporting hypothesis 1. A firm that takes strategic risk tends to improve its performance in the following period. This result agrees with the results of Miller and Leiblein's (1996) and contradicts the negative risk-return relations supported by some previous research using variability measures of risk. Specifically, strategic risk is rewarded with higher future performance.

\footnotetext{
${ }^{4}$ One approach for assessing collinearity is the calculation of variance inflation factors (VIFs). A VIF greater than 10 is often interpreted as an indication of collinearity problems (Neter, Wasseman, \& Kutner, 1985). Conditioning indexes provide a supplemental collinearity diagnostic. Belsey et al. (1980) suggested that conditioning indexes in the neighborhood of 15 to 20 tend to result from an underlying near dependencies among explanatory variables and that indexes in excess of 100 cause substantial variance inflation and potential large distortions in regression coefficients. For the four regressions presented in Tables 2 and 3, the maximum VIF was 1.06. The maximum conditioning index was 7.27.
} 
Hypothesis 3 states that organizational slack should have a negative relation with subsequent financial performance. The significant positive coefficients associated with the slack variable in Table 2 support this hypothesis. Slack facilitates organizational responses to strategic risk, enhancing subsequent performance. Lowslack firms may be constrained in their ability to implement successful searches for new organizational strategies. The control variables, lagged return and contemporaneous industry return, have the expected significant positive relations with return.

The results shown in Table 3 shed light on Hypothesis 2 and 4. Hypothesis 2 states that financial performance should have a negative relation with subsequent ordinal strategic risk. As the behavioral theory of the firm suggests, firms performing well avoid the cost and uncertainty associated with searching for alternative strategies. The strategic risk model provides strong support for this hypothesis in all two periods (Table 3 ).

Hypothesis 4 states that organizational slack would be negatively related with subsequent strategic risk. Slack would act as a buffer allowing firms to reduce subsequent strategic risk. The insignificant coefficients shown in Table 3 do not support this hypothesis. Furthermore, the slack effect has not the expected negative sign. Slack resources do not allow firms to reduce their subsequent strategic risk. One potential explanation is that the relation between slack and ordinal strategic risk is nonlinear, with both high and low levels of slack associated with high levels of risk and moderate levels of slack associated with high levels of risk. Slack levels well above or below a firm's reference level should increase risk taking, and slack levels near the reference level should reduce it. The ordinal strategic model, as specified in equation [2], does not allow testing for this proposition.

Contemporaneous industry ordinal strategic risk has the expected positive sign but it is not significant at the .05 level in the two periods studied (Table 3). Although the contemporaneous industry risk effect is not significant, which is counterintuitive, these results support inclusion of both controls. Some previous studies have found significant positive effects of contemporaneous industry risk (e.g. Miller and Leiblein, 1996) but they were not significant across periods.

The positive relation of risk and subsequent return, using the ordinal strategic risk measure and the negative influence of return on risk are consistent and significant across the two periods. These results agree with the results of Miller and Leiblein's (1996). This pattern suggest an interesting sequence in agreement with the behavioral theory of the firm: taking strategic risk results in higher performance, but higher performance leads to less strategic risk taking. Using ordinal strategic risk, we have a self-correcting cycle that contrasts with the "vicious circle" hypothesized in previous research on Bowman's (1980) risk-return paradox. Research applying prospect theory has contended that poorly performing firms take "bad risks" and that worse performance results (Bowman, 1982; Fiegenbaum and Thomas, 1988; Jegers, 1991). Using ordinal strategic risk, we did not find evidence of such a downward spiral. On the contrary, we found that poor performers often take what Miller and Leiblein (1996: 114) defined as "good risks".

\section{DISCUSSION}

The most common approach in strategic management studies has been to employ the variance of a set of returns over time as a risk measure. Using rigorous statistical grounds, Ruefli (1990) contended that variance-mean relations were not meaningful. As noted by Lehner (2000: 67), mean-variance analysis is useful only under certain conditions-for example, when returns are normally distributed. Some recent studies have demonstrated that skewness of return distributions and serial dependence of performance can lead to spurious negative relationships between risk and return (Henkel, 2003; Denrell, 2004). Managerial surveys (e.g. Baird and Thomas, 1990; March and Shapira, 1987) suggest that downside concepts of risk, those specified in terms of failure to perform at a targetto level, are much more relevant to practicing managers than performance variability, which includes both upside and downside outcomes. This debate regarding the appropriateness of variance measures is critical to evaluating the findings of prior strategy research incorporating variance measures of risk, such as research on corporate risk-return relations. In recognition of both the controversy regarding the conceptual validity of variance risk measures and the problem of unclear causality between risk and return, we have specified and tested a dynamic model of corporate 
risk taking in which risk is based upon the chance of loss of relative position within a set of firms rather than outcome variance.

As Miller and Leiblein's, our results challenge a major contention of previous research based on prospect theory, namely, the idea that poor performers take on risky strategies (high variance) with low expected values. Such risk-seeking behavior can be shown to increase the probability of firm survival despite reducing expected returns (Singh, 1986). Using a fundamentally different concept of risk -ordinal strategic risk- results in a very different pattern of risk-return relations. The evidence from this study indicates strategic risk leads to organizational strategic changes that improve, rather than reduce, subsequent firm performance. Our results indicate that this relation is strengthened by the presence of slack resources. Combining the results from the return and strategic risk equations indicates a self-correcting, rather than downward spiraling, cycle involving performance and strategic risk.

The regression results also shed light on the role of slack resources in determining firm performance and strategic risk. The empirical evidence indicates that slack does not appear to play a role in determining firm risk taking. This result contradicts the contention that slack acts as a buffer reducing firm performance and risk-taking. These observations should motivate broader interest in ordinal strategic risk among strategy researchers. The initial results from this study encourage wider empirical treatments of ordinal strategic risk.

As noted by Miller and Bromiley (1996), the behavioral theory, as a theory of organizational risk-return relations, suffers from two important shortcomings. First, since behavioral theory seeks to explain risk as a managerial choice, it neglects unchosen risks. Such a perspective acknowledges that managers and environments jointly determine risk-return relations. Second, strategic actions mediate the relations between strategic risk and performance from one period to the next. Good managers are risk seekers and support innovative behaviors that encourage the firm's capacity to adapt to environmental change (Fiegenbaum and Thomas, 2004; Miller and Chen, 2003). The behavioral theory, however, does not illuminate the content of these strategic actions. Explicit attention to the mediating strategic responses is thus essential to advancing research on strategic risk.

These two observations suggest the ordinal strategic risk measure has applications beyond the parsimonious model tested here. Although research on risk-return relations has revealed the measurement properties of alternative risk measures (e.g. Bromiley, 1991; Miller and Bromiley, 1990; Ruefli, 1990; Ruefli et al., 1999; Wiseman and Bromiley, 1991), it has done little to inform managerial decisions. The relations between firm strategy, industry structure, risk, and performance found in previous research (e.g. Amit and Wernerfelt, 1990; Oviatt and Bauerschmidt, 1991) could be reanalyzed from an ordinal strategic risk perspective.

This study focused on the managerial perspective and emphasized a firm-specific ordinal strategic risk measure incorporating accounting returns, but shareholders may be more interested in the downside stock returns variability of a diversified portfolio. We might postulate that steps taken to address agency problems, such as changes in governance structures, monitoring, and management compensation systems, can result in managerial attention to maximizing shareholder returns rather than minimizing strategic risk. As suggested by Miller and Chen (2004: 113), managers can err either by excessive risk taking (type error I) or insufficient risk taking (type error II). Monitoring and compensation systems bring managerial risk taking in line with the interests of shareholders. Wright et al. (2007) showed that managerial option incentives are directly and uniformly related to subsequent firm risk taking. As argued by the authors (2007: 88), at substantial values of these incentives managerial decisions may become unduly influenced by a risk aversion predisposition, harming the interests of external shareholders. Future research may shed light on the moderating effects of agency theory variables on managerial decisions affecting strategic risk and return. Incorporation of an ordinal strategic risk measure into other areas of organizational research may prove fruitful.

\section{REFERENCES}

1. Aaker, D.A., \& Jacobson, R. 1987. The role of risk in explaining differences in profitability. Academy of Management Journal, 30: 277-296. 
2. Amit R., \& Wernerfelt B. 1990. Why do firms reduce business risk? Academy of Management Journal, 33: 520-533.

3. Andersen, T.J, Denrell, J. \& Bettis R.A. 2007. Strategic responsiveness and Bowman's risk-return paradox. Strategic Management Journal, 28: 407-429.

4. Baird, I.S., \& Thomas, H. 1990. What is risk anyway? Using and measuring risk in strategic management. In Risk, Strategy and Management, Bettis R.A. \& Thomas H. (eds.). Greenwich, CT: JAI Press, 21-51.

5. $\quad$ Belsley, D.A., Kuh, E., \& Welsch, R.E. 1980. Regression diagnostics. New York: Wiley.

6. Bourgeois, L.J. 1981. On the measurement of organizational slack, Academy of Management Review, 6: 2939.

7. Bourgeois, L.J., \& Singh, J.V. 1983. Organizational slack and political behavior within top management groups. Academy of Management Proceedings: 43-49.

8. $\quad$ Bowman, E.H. 1980. A risk/return paradox for strategic management, Sloan Management Review, 21: $27-$ 31.

9. $\quad$ Bowman, E.H. 1982. Risk seeking for troubled firms, Sloan Management Review, 23: 33-42.

10. Bromiley, P. 1991. Testing a causal model of corporate risk taking and performance, Academy of Management Journal, 34: 37-59.

11. Bromiley, P., Miller, K.D., \& Rau, D. 2001. Risk in strategic management research. In The Blackwell Handbook of Strategic Management, Hitt M.A., Freeman R.E., \& Harrisson, J.S. (eds). Blackwell: Malden, MA; 259-288.

12. Cohen, M.D., March, J.G., \& Olsen, J.P. 1972. A garbage can model of organizational choice, Administrative Science Quarterly, 17: 1-25.

13. Collins, J.M., \& Ruefli, T. 1992. Strategic risk: An ordinal approach, Management Science, 38: 1707-1731.

14. Cyert, R.M., \& March, J.G. 1963. A behavioral theory of the firm. Englewood Cliffs, NJ: Prentice-Hall.

15. Denrell, D.J. 2004. Risk taking and aspiration levels: two alternative null models. Academy of Management Best Paper Proceedings, New Orleans, LA.

16. Fiegenbaum, A., \& Thomas, H. 1986. Dynamic and risk measurement perspectives on Bowman's riskreturn paradox for strategic management: An empirical study, Strategic Management Journal, 7: 395-408.

17. Fiegenbaum, A., \& Thomas, H. 1988. Attitudes toward risk and the risk-return paradox: Prospect theory explanations, Academy of Management Journal, 31: 85-106.

18. Fiegenbaum, A., \& Thomas, H. 2004. Strategic risk and competitive advantage: an integrative perspective, European Management Review, 1: 84-95.

19. Fisher, I.N., \& Hall, G.R. 1969. Risk and corporate rates of return, Quarterly Journal of Economics, 83: 7992.

20. Hannan, M.T., \& Freeman, J.H. 1977. The population ecology of organizations, American Journal of Sociology, 82: 929-964.

21. Henkel, J. 2003. The risk-return paradox for strategic management: disentangling true and spurious effects. Paper presented at the annual meeting of the Academy of Management, Seattle, WA.

22. Jegers, M. 1991. Prospect theory and the risk-return relation: Some Belgian evidence, Academy of Management Journal, 34: 215-225.

23. Kahneman, D., \& Tversky, A. 1979. Prospect theory: An analysis of decision under risk, Econometrica, 47: 262-291.

24. Lant, T.K. 1992. Aspiration level adaptation: An empirical exploration, Management Science, 38: 623-644.

25. Lant, T.K., \& Montgomery, D.B. 1987. Learning from strategic success and failure, Journal of Business Research, 15: 503-517.

26. Lehner, J.M. 2000. Shifts of reference points for framing of strategic decisions and changing risk-return associations, Management Science, 46: 63-76.

27. Lev, B. 1969. Industry averages as targets for financial ratios, Journal of Accounting Research, 7: 290-299.

28. MacCrimmon, K.R., \& Wehrung, D.A. 1986. Taking risks: The management of uncertainty. New York: Free Press.

29. March, J.G., \& Shapira, Z. 1987. Managerial perspectives on risk and risk taking, Management Science, 33: 1404-1418.

30. Miller, K.D., \& Bromiley, P. 1990. Strategic risk and corporate performance: An analysis of alternatives risk measures, Academy of Management Journal, 33: 756-779. 
31. Miller, K.D. \& Chen, W. 2003. Risk and firms' costs, Strategic Organization, 1: 355-382.

32. Miller, K.D. \& Chen, W. 2004. Variable organizational risk preferences: Tests of the March-Shapira model, Academy of Management Journal, 47: 105-115.

33. Miller, K.D., \& Leiblein, M.J. 1996. Corporate risk-return relations: Returns variability versus downside risk, Academy of Management Journal, 39: 91-122.

34. Neter, J., Wasserman, W., \& Kutner, M.H. 1985. Applied linear statistical models. Homewood, IL: Irwin.

35. Nickel, M.N., \& Rodriguez, M.C. 2002. A review of research on the negative accounting relationship between risk and return: Bowman's paradox. Omega, 30: 1-18.

36. Oviatt, B.M., \& Bauerschmidt, A.D. 1991. Business risk and return: A test of simultaneous relationships, Management Science, 37: 1405-1423.

37. Ruefli, T.W. 1990. Mean-variance approaches to risk-return relationships in strategy: Paradox lost, Management Science, 36: 368-380.

38. Ruefli, T.W., Collins, J.M., \& Lacugna, J.R. 1999. Risk measures in strategic management research: Auld lang syne, Strategic Management Journal, 20: 167-194.

39. Ruefli, T.W, \& Wilson, C. 1987. Ordinal time series methodology for industry and competitive analysis, Management Science, 33: 640-661.

40. Shannon, C.E., \& Weaver, W. 1949. The Mathematical Theory of Communication. Urbana, IL: University of Illinois Press.

41. Singh, J.V. 1986. Performance, slack, and risk taking in organizational decision making, Academy of Management Journal, 29: 562-585.

42. Thompson, J.D. 1967. Organizations in action. New York: MacGraw-Hill.

43. Wang, H., Barney, J.B., \& Reuer, J.J. 2003. Stimulating firm-specific investment through risk management, Long Range Planning, 36: 49-59.

44. Wiseman, R.M., \& Bromiley, P. 1991. Risk-return association: Paradox or artifact? An empirically tested explanation, Strategic Management Journal, 12: 231-241.

45. Wright, P., Kroll, M., Krug, J.A. \& Pettus, M. 2007. Influences of top management team incentives on firm risk taking, Strategic Management Journal, 28: 81-89.

\section{APPENDIX}

- Step 1. Building the Aggregated Matrix of Events, $\Phi=\left[\Phi_{\mathrm{I}, \mathrm{J}, \mathrm{K}, \mathrm{T}}\right]$

We build a matrix of events, $\boldsymbol{\Phi}_{i}$, for each of the 40 firms forming the system (the CAC 40, a French stock market index) from the ordinal coding of the annual profitability of their ROA over the 5-year periods 1988-92, 1993-97, and 1998-02. If all of the matrices, $\boldsymbol{\Phi}_{i}$, describing individual firms are summed over $i$, then a matrix, $\Phi=$ $\left[\sum_{i} \phi_{i, j, k}\right]=\left[\phi_{\cdot, j, k}\right]$, which describes the incidence of state transitions for the entire system is created.

- Step 2. Building the Joint Transition Matrix, $\mathbf{P}=\left[\mathrm{p}_{j, k}\right]$

We build the joint transition probabilities matrix for the system, $\mathbf{P}=\left[\mathrm{p}_{j, k}\right]$, whose elements are the joint frequencies: $p_{j, k}=\frac{\phi_{\cdot, j, k}}{\phi ., ., .}$. This is accomplished by dividing each element of the matrix of events, $\boldsymbol{\Phi}$, by the total number of transitions. The total number of transitions is 160 (i.e., 40 firms $\times 4$ possible transitions for each firm) for each fiveyear period. This matrix $\mathbf{P}$ describes the joint probabilities derived from the state transitions. For example, $p_{2, l}$ is simply the probability that a firm selected at random will move from category two to category one in the next period (here, the following year).

- $\quad$ Step 3. Building the Joint Entropy Matrix derived from the matrix $\mathbf{P}$

We use the transition probabilities to calculate the total uncertainty of the system. This is accomplished by reference to the information theoretic concepts provided by Shannon and Weaver (1949). The entropy of the system, $H_{(\mathrm{J}, \mathrm{K})}$, where $\mathrm{J}$ is the initial row and $\mathrm{K}$, the final row, is calculated from (Eq. 1): 


$$
H_{(J, K)}=\sum_{j=1}^{n}-\left[\sum_{k=1}^{n} p_{j, k} \ln \left(p_{j, k}\right)\right], \text { where } p_{j, k} \geq 0, \quad \sum_{j=1}^{n} \sum_{k=1}^{n} p_{j, k}=1
$$

As a result, we obtain the joint entropy matrix derived from the matrix $\mathbf{P}$. The total joint entropy of this matrix of joint entropies is calculated by summing all of the individual cell entropies.

- Step 4. Building the Conditional Entropy Matrix

We transform the joint transition probabilities matrix into a conditional transition probabilities matrix, identical in form to a Markov matrix. Denoting the probability of moving to category $k$, given that the firm is now in category $j$ by $p_{(\mathrm{k}, \mathrm{j},}$, this is accomplished by dividing each entry in the joint probability matrix by the sum of the joint probabilities in its row. For any given category classification, $k$, the conditional probabilities associated with prior knowledge of starting category are:

$$
\begin{gathered}
p_{(k / j)}=\frac{p_{j, k}}{p_{j, .}} \text { where } p_{j, .}=\sum_{k=1}^{n} p_{j, k} \\
\text { and } p_{(k / j)} \geq 0, \quad \sum_{j=1}^{n} p_{(k / j)}=1, \quad \sum_{j=1}^{n} \sum_{k=1}^{n} p_{(k / j)}=n .
\end{gathered}
$$

We can then build the conditional entropy matrix, whose elements are the products:

$$
p_{(k / j)} \times \ln \left[p_{(k / j)}\right] \text {. }
$$

In any case the conditional entropy associated with starting category $j=y$ is defined by (Eq.2):

$$
h_{(k / j=y)}=-\sum_{k=1}^{n} p_{(k / j=y)} \ln \left[p_{(k / j=y)}\right]
$$

The average conditional entropy of the system is simply the weighted sum of the entropies of each of the conditional distributions in each row. It is defined by (Eq. 3):

$$
H_{(K / J)}=-\sum_{j=1}^{n} \sum_{k=1}^{n} \frac{1}{n} p_{(k / j)} \ln \left[p_{(k / j)}\right]
$$

\section{- Step 5. Computing the total uncertainty of the system}

We calculate the weighted average conditional entropy, $H W_{(\mathrm{K} / \mathrm{J})}$, a measure of the total uncertainty of the system, defined by (Eq.4):

$$
H W_{(K / J)}=-\sum_{j=1}^{n} \sum_{k=1}^{n} w_{j, k} \frac{1}{n} p_{(k / j)} \ln \left[p_{(k / j)}\right]
$$

Since the weighted average conditional entropy measure takes into account the qualitative aspect of the seriousness of category shift (via the weights $w_{\mathrm{j}, \mathrm{k}}$ ), $H W_{(\mathrm{K} / \mathrm{J})}$ provides a measure of the level of uncertainty associated with the system's member's behavior. The total uncertainty, as defined by (Eq. 4), links the probability of occurrence of three distinct performance events in the system: (i) degradation of the row of classification, (ii) improvement of the row of classification, and (iii) stability of the row of classification.

\section{- $\quad$ Step 6. Computing Ordinal Strategic Risk for an individual firm $i$}

Equation (Eq. 5) below gives the analytic formulation of ordinal strategic risk for a firm $i$, denoted $R I S K_{i(K / J)}$. It is defined as the difference between the ordinal strategic risk which is attributable to an individual firm $i$, denoted $H W R_{i(K / J)}$, and an ordinal measure of system risk, i.e., the system riskiness of the reference set of firms as a whole (a sample of 40 firms), denoted $H W R_{(K / J)}$. Ordinal strategic risk for an individual firm is measured relatively to a target level or benchmark. The term $H W R_{(K / J)}$ in equation (Eq. 5) may serve as a proxy for this strategic risk benchmark, since it corresponds to the system riskiness or total risk of the reference set of firms. 
$\operatorname{RISK}_{i(K / J)}=H W R_{i(K / J)}-H W R_{(K / J)}$

with:

$H W R_{i(K / J)}=-\sum_{j=1}^{n} \sum_{k>j}^{n} w_{j, k} \frac{1}{n}\left[\frac{\phi_{i, j, k}}{\phi_{., j, .}}\right] \ln \left[p_{(k / j)}\right]$

and

$H W R_{(K / J)}=-\sum_{j=1}^{n} \sum_{k>j}^{n} w_{j, k} \frac{1}{n} p_{(k / j)} \ln \left[p_{(k / j)}\right]$

After simplification, equation (Eq. 5) may be written as follows:

$R I S K_{i(K / J)}=-\frac{1}{n} \sum_{j=1}^{n} \sum_{k>j}^{n} w_{j, k} \ln \left[p_{(k / j)}\right]\left[\frac{\phi_{i, j, k}}{\phi_{., j, .}}-\frac{1}{n} p_{(k / j)}\right]$

Ordinal strategic risk for each of the 40 firms included in the sample (or system) was computed using equation (Eq. 5.3), where:

- $w_{j, k}$ is a weight function generated by making the assumption that seriousness of loss of position is directly proportional to the number of positions lost.

- The $p_{(k / j)}$ denote the conditional probabilities of any transition events from rank $j$ to rank $k$ in the system.

- $\quad \phi_{i, j, k}$ is the total number of transitions made by firm $i$ from rank $j$ to rank $k$.

- $\quad \phi_{., j, .}$ is the sum of transitions that start in category $j$ for all entities in the system. 


\section{NOTES}

